\title{
WANDERING IN SCOPIMERA GLOBOSA (CRUSTACEA : OCYPODIDAE)
}

AUTHOR(S):

Wada, Keiji

\section{CITATION:}

Wada, Keiji. WANDERING IN SCOPIMERA GLOBOSA (CRUSTACEA: OCYPODIDAE). PUBLICATIONS OF THE SETO MARINE BIOLOGICAL LABORATORY 1981, 26(4-6): 447-454

\section{ISSUE DATE:}

1981-09-30

URL:

http://hdl.handle.net/2433/176027

RIGHT: 


\title{
WANDERING IN SCOPIMERA GLOBOSA (GRUSTAGEA: OGYPODIDAE) $)^{1)}$
}

\author{
KEIJI WADA \\ Seto Marine Biological Laboratory \\ With Text-figures $1-2$ and Table 1
}

\section{Introduction}

Scopimera globosa De Haan is one of the commonest ocypodid crabs that inhabit estuaries and bays in Japan. It mostly occurs around the high water mark on the sandy or muddy sand shore. It is relatively small, and shows the sexual difference in the maximum size, namely about $10 \mathrm{~mm}$ in carapace breadth in males whereas about $8 \mathrm{~mm}$ in females. The reproductive period is from April through August in the estuary of Waka River, Wakayama, middle Japan (Wada, 1981).

Each crab usually has its own burrow and at the daytime low tide it comes out from its burrow to engage in various activities on the surface such as feeding or waving, with intermittent recession into its burrow. There are also often found wandering crabs which do not have their own burrows. While wandering they show feeding activities and when men or other enemies approach, they flee into the nearest burrows owned by other crabs or in the water-logged place they hide themselves in the sand. Their movements are usually directed to the lower level at ebb tide, while to the upper level at flood tide. On occasion, such wanderers are in mass as reported by Sugiyama (1961), Ono (1965), and Yamaguchi and Tanaka (1974).

In this paper, the results of observation on wandering crabs are reported, particularly to show seasonal aspects of wandering and to elucidate several features differing from the previous descriptions on mass wandering, and the conditions that originate wandering are considered.

I wish to thank Prof. E. Harada and Dr. M. Nishihira of Kyoto University who read the manuscript and provided constructive criticism. In addition, I have profited from discussions about the study with the members of the Seto Marine Biological Laboratory, Prof. I. Maki and Dr. K. Iwata of Wakayama University, and Prof. H. Kawanabe and Mr. A. Taki of Kyoto University.

\section{Methods}

The protected sandy tidal flat at Fujishima in the inner part of Tanabe Bay.

1) Contributions from the Seto Marine Biological Laboratory, No. 678.

Publ. Seto Mar. Biol. Lab., XXVI (4/6), 447-454, 1981.

(Article 25) 


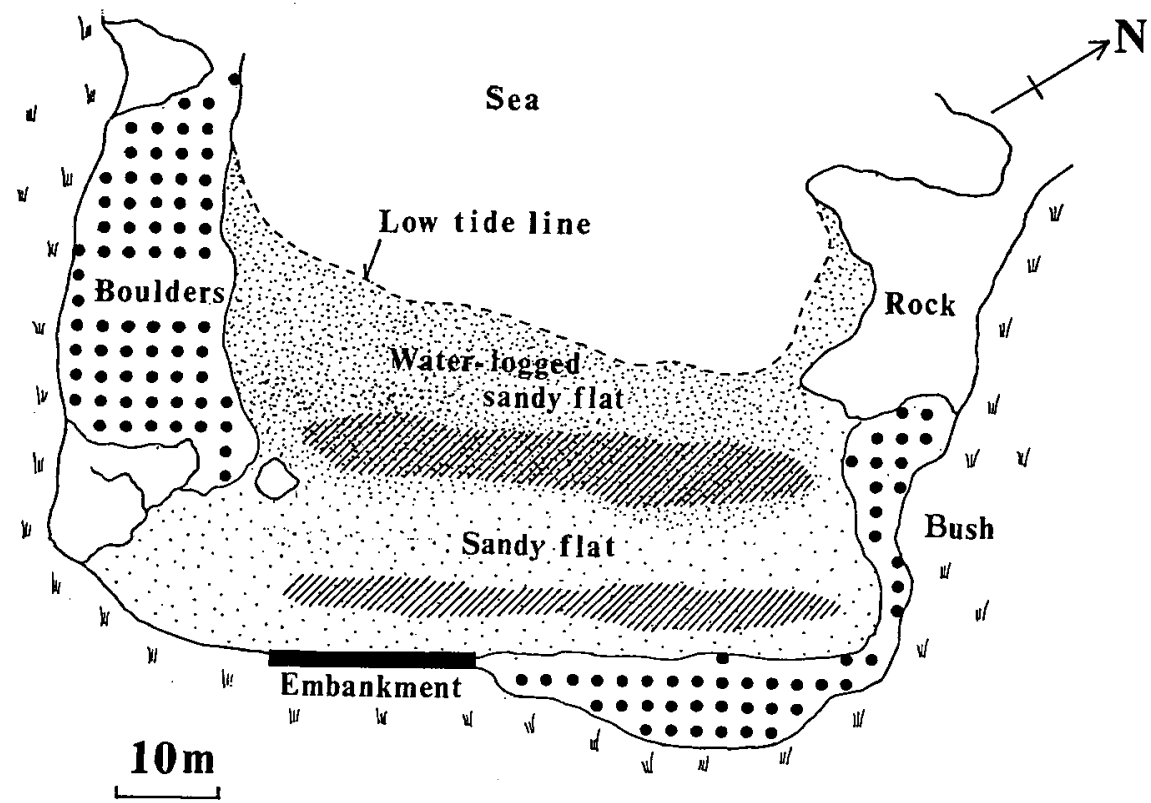

Fig. 1. Sketch map of the study area at Fujishima, Tanabe Bay. The hatched areas show the ranges of the upper and the lower places where crabs were captured at low tide.

was selected for the seasonal observation of wandering crabs (Fig. 1). The tidal flat, which was bordered by the embankment and boulder shores on the landward side, was 20 to $40 \mathrm{~m}$ wide at spring low tide. The zone of 8 to $15 \mathrm{~m}$ from the embankment was flat and well drained, whereas the succeeding seaward zone was water-logged, with the surface having ripple mark and partly covered with stranded Ulva pertusa. Besides $S$. globosa no other ocypodids were found in this area except a few individuals of Ocypode stimpsoni. S. globosa mainly inhabited the upper welldrained place.

During the spring tide periods of 15-17 June, 14-15 August, 9 September, 1976 and 6-7 May, 1-3 June, 1977, when the weather was fine, the behaviors of wandering crabs were observed for more than thirty minutes during each time of ebb, low and flood tides. In addition, excepting newly settled juveniles, about one hundred burrow owners were captured at the upper place and the similar number of both burrow owners and wanderers at the lower water-logged place around low tide time (Fig. 1), and the sex; the carapace breadth and the reproductive condition of the females were recorded. Carapace breadth was measured between the incisions of the anterolateral margins which is not the widest part of carapace.

When I encountered mass wandering in any regions other than Fujishima from 1973 to 1977 , the date, the weather and whether the members of wanderers were large or medium-sized crabs or small ones, were recorded. If possible, some wandering crabs were captured to check the sex, and burrows were counted at the neighboring higher density site in four or five quadrats, measuring $50 \mathrm{~cm} \times 50 \mathrm{~cm}$. 


\section{Results}

Wanderers and Mass Wandering in Fujishima

(I) June 1976

At ebb tide, numerous medium-sized crabs were observed to wander feeding toward the water edge. They progressed characteristically in short spurts nearly in a straight line and not in puttering about. 24 wandering crabs collected included one male and 23 non-ovigerous females, 21 of which were spent. During seaward wandering, they were often observed to be chased or seized and carried by males, or to copulate with males. As low tide approached, some wandering crabs at the lower water-logged place constructed burrows, mostly of $3 \mathrm{~cm}$ depth and curved at the bottom.

At low tide, the lower water-logged place was occupied by many non-ovigerous females and a few males, whereas many males and a few females including ovigerous ones were resident at the upper place (Fig. 2). Among nine ovigerous females collected from the upper place, six carried eyed eggs and the others uneyed ones. It was also observed that some males chased or carried females, or copulated.

On flooding, many crabs wandered toward the upper place. These wanderers contained the crabs which had owned their burrows at the lower place. On the other hand, there were also some closed burrows at the lower place, which were found occupied by crabs, on digging. It was frequently observed that wandering females, on the way to the upper place, were chased or seized and carried by males, or was forced to copulate. As an example, a wandering female copulated with a male two times successively and after that she still copulated two times with other two different males during the flood tide time of $17: 10$ to $17: 24$ on 16 June.

\section{(II) August and September 1976}

In both months, the population included newly settled juveniles. At ebb tide, numerous juveniles were seen to wander toward the lower place. Some other juveniles, however, remained at the upper place, owning their burrows. In adults, on the contrary, such seaward wandering was not so remarkable in both months. At low tide, the lower place was occupied not only by juveniles but also by many females and some males in August, while the small males were abundant there in September (Fig. 2). Both adults and juveniles occurring at the lower place consisted of the wanderers and the burrow owners in both months. At flood tide, the landward wandering of some adults and many juveniles were observed.

Sexual behaviors, which were frequently observed in June, were not witnessed during the survey in both months.

On 15 August, 10 to 20 burrows and on 9 September, 20 to 30 ones were counted per $50 \mathrm{~cm} \times 50 \mathrm{~cm}$ at the higher density site.

(III) May and June 1977

The seaward and landward wandering at ebb and flood tides were recognized also in these months but they were not so remarkable as in June of 1976. At low 


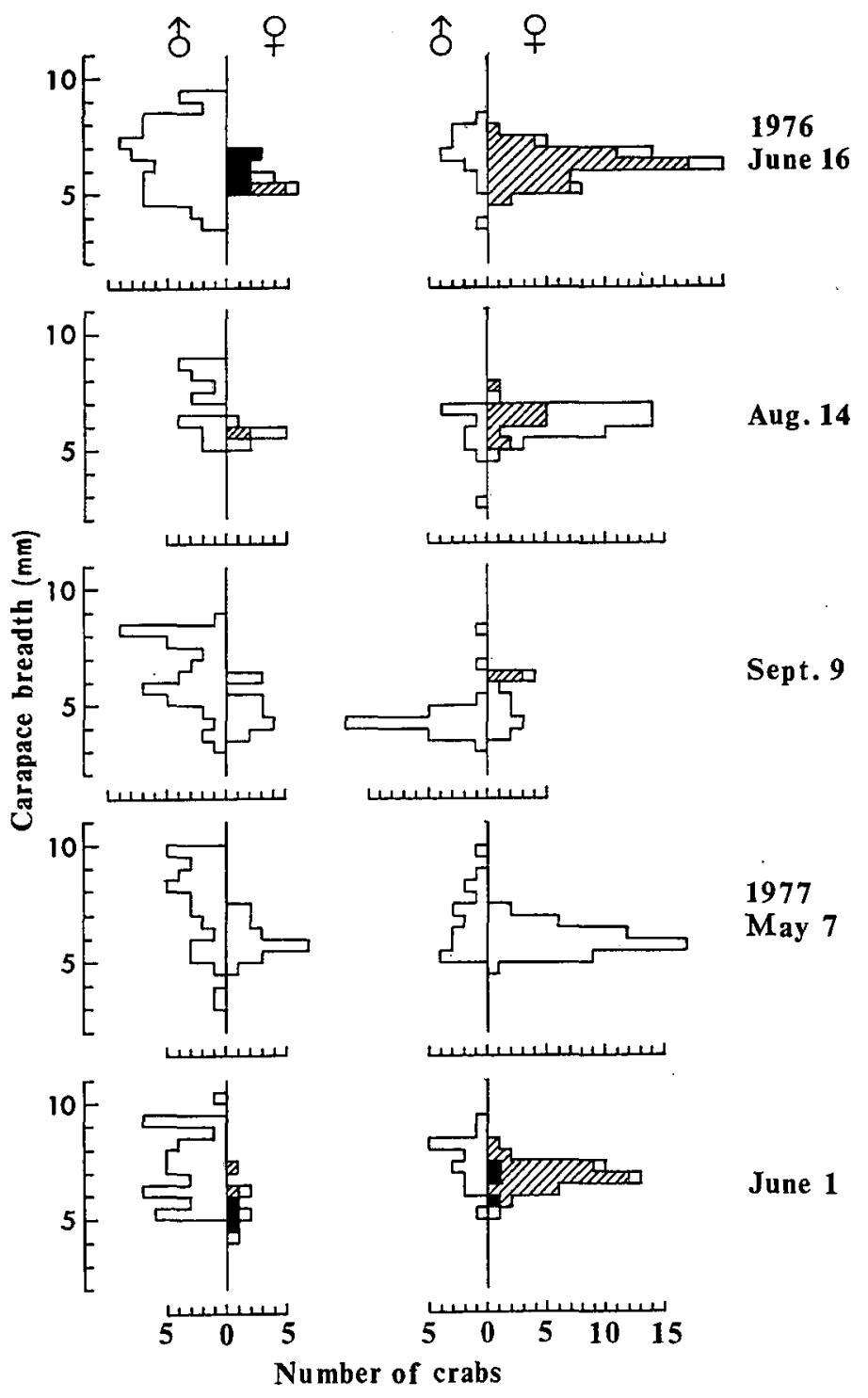

Fig. 2. Size frequency distributions of sexable Scopimera globosa collected from the upper (left) and the lower place (right). The solid and the hatched histograms indicate the ovigerous and the spent females, respectively.

tide, the lower water-logged place was occupied by many females and some males, while at the upper place males occurred predominantly (Fig. 2). The ovigerous females were collected from both the upper and the lower places. And among them, all three from the upper place carried uneyed eggs while two from the lower place carried eyed eggs and one uneyed eggs. Most of the crabs occurring at the lower place were burrow owners. On flooding, many of the burrows at the lower place were closed, being occupied by crabs. 
The sexual behaviors were frequently observed at ebb, low and flood tides as in June of 1976.

On 1 June, 9 to 15 burrows were counted per $50 \mathrm{~cm} \times 50 \mathrm{~cm}$ at the higher density site.

\section{Mass Wandering on Other Shores}

Table 1 enumerates mass wanderings which I witnessed on various shores excluding Fujishima from 1973 to 1977.

Table 1. The record of mass wanderings of Scopimera globosa which were observed from 1973 to 1977. The figures in parentheses show the number of the males (left) and that of the females (right) collected randomly from the wanderers. Burrow density was taken at the upper place of relatively higher density in the neighborhood of the mass of wanderers. All the localities except Tsuyazaki (Fukuoka Prefecture) are situated in Wakayama Prefecture. Abbreviations for wandering crabs are: L, large or medium-sized crabs; S, small crabs.

\begin{tabular}{|c|c|c|c|c|c|c|c|}
\hline & Date & $\begin{array}{c}\text { Age of } \\
\text { moon }\end{array}$ & Locality & Weather & $\begin{array}{l}\text { Tem- } \\
\text { perature } \\
\left({ }^{\circ} \mathrm{C}\right)\end{array}$ & Wandering crabs & $\begin{array}{l}\text { Burrow density } \\
\text { (per } \\
50 \mathrm{~cm} \times 50 \mathrm{~cm} \text { ) }\end{array}$ \\
\hline 1973 & Nov. 10 & 15.0 & Waka River & Fine & & $\mathrm{L}$ & $100-130$ \\
\hline \multirow[t]{3}{*}{1974} & Jun. 19 & 28.3 & Waka River & Fine & & $\mathrm{L}$ & \\
\hline & Jun. 20 & 29.3 & Waka River & Fine & & $\mathrm{L}$ & \\
\hline & Aug. 5 & 16.6 & Waka River & Fine & 28.5 & $\mathbf{S}$ & \\
\hline \multirow[t]{4}{*}{1975} & Jul. 7 & 27.3 & Waka River & Gloudy and rainy & 29 & $\mathbf{L}$ & \\
\hline & Jul. 8 & 28.3 & Egami River & Fine & & $\mathrm{L}$ & \\
\hline & Aug. 3 & 25.0 & Tsuyazaki & Fine & 34 & $\mathbf{L}$ & $90-102$ \\
\hline & Oct. 3 & 27.3 & Waka River & Cloudy and rainy & & $\mathrm{L}$ and $\mathrm{S}$ & \\
\hline \multirow[t]{8}{*}{1977} & May 18 & 0.0 & Waka River & Fine & 26 & $\mathbf{L}$ & \\
\hline & May 19 & 1.0 & Waka River & Fine & 24.9 & $L(32: 18)$ & \\
\hline & May 19 & 1.0 & Waka River & Fine & & L $(19: 34)$ & $38-57$ \\
\hline & May 20 & 2.0 & Waka River & Fine & & L $(39: 63)$ & \\
\hline & Jun. 5 & 18.0 & Shirahama & Fine & & $L(51: 24)$ & \\
\hline & Oct. 11 & 27.7 & Waka River & Fine & & $L$ & $39-49$ \\
\hline & Oct. 11 & 27.7 & Waka River & Fine & 20.5 & $\mathrm{~L}$ and $\mathrm{S}(34: 68)$ & $41-81$ \\
\hline & Oct. 11 & 27.7 & Waka River & Fine & & $\mathrm{L}(15: 45)$ & $96-142$ \\
\hline
\end{tabular}

Mass wandering was encountered in May, June, July, August, October and November. In most cases the wanderers consisted of large or medium-sized crabs but there were also some masses that included newly settled juveniles. In four of six cases in May and October, 1977, females were about twice as many as males, while in the rest two, males about twice as many as females.

All of mass wanderings listed occurred at the lower and water-logged places, with the members being devoted to feeding actively. Mass wandering was encountered not only on calm and fine days, but also when the weather was windy and cloudy with intermittent raining. The burrow density in the neighborhood of mass wandering showed the various values from more than 100 to less than 50 per $50 \mathrm{~cm} \times 50 \mathrm{~cm}$. The substratum where mass wandering was seen was not only wholly sandy from 
the upper to the lower place, but also sandy at the upper and muddy at the lower. In the latter case, the wanderers were seen at the relatively upper sandy place at the ebb and flood tides, but not at the lower muddy place.

\section{Discussion}

While wandering crabs are usually seen among the population members of $S$. globosa, it is not common that they are in mass as reported here from Fujishima and other shores. The surrounding conditions of mass wandering, however, can be analysed and understood as giving some clues to the consideration of the origin of wandering.

As to mass wandering of $S$. globosa, the following has been reported: 1) the period of its appearance was from the end of July to the beginning of August at Urayasu of Chiba Prefecture (Sugiyama, 1961) and from May to August at Amakusa, Kyushu (Yamaguchi and Tanaka, 1974), 2) the members were mainly larger crabs (Sugiyama, 1961; Yamaguchi and Tanaka, 1974) and the sex ratio was approximately 1 to 1 (Yamaguchi and Tanaka, 1974), 3) it invariably occurred at the water-logged place near the water edge (Sugiyama, 1961; Ono, 1965; Yamaguchi and Tanaka, 1974), and 4) it was attributed to more intensive interactions between individuals due to overcrowding, because it was observed in the high density area on warm and fine days when crabs were active, and moreover because the larger crabs predominating in the wanderers were supposed to be more exclusive than the smaller (Sugiyama, 1961; Ono, 1965; Yamaguchi and Tanaka, 1974).

According to the results of my observations in Fujishima, numerous mediumsized and small crabs wandered. And at low tide the lower place was occupied predominantly by females or smaller crabs in all the survey months. In mass wanderings on other shores, there were also some cases in which females or juveniles dominated in numbers. In addition, mass wandering was encountered also in relatively low density areas where less than 50 burrows per $50 \mathrm{~cm} \times 50 \mathrm{~cm}$ were recorded at most. It was observed also on the windy and intermittently raining days when crabs were supposed to be less active than on fine days. Thus, it seems that overcrowding and resulted interactions only can not be taken as the cause of mass wandering.

Mass wandering has been well-known also in other ocypodids, such as Dotilla mictyroides (Tweedie, 1950), D. ausgedehnte (Altevogt, 1957), Uca tangeri (Altevogt, 1959; v. Hagen, 1962), U. vocator (v. Hagen, 1970), U. rapax (v. Hagen, 1970), and U. vocans vocans (Nakasone, 1977). Mass wandering of all these species was reported to occur on the water-logged place. It was also reported for wanderers that the males were dominant in $U$. vocans vocans (Nakasone, 1977) or about as many as the females in $U$. tangeri (v. Hagen, 1962), and that the ovigerous females occasionally formed the mass in $U$. vocator (v. Hagen, 1970). No observations are available that the mass of wanderers mainly consisted of non-ovigerous females or juveniles as in $S$. globosa reported in this paper. In these ocypodids excluding $S$. globosa, mass wandering has been generally interpreted in such a way that the deficiency of the water indis- 
pensable for feeding (Miller, 1961) due to the dryness of the substratum caused the crabs to wander toward the lower water-logged place (Altevogt, 1959; Miller, 1961; Nakasone, 1977). For mass wandering in $S$. globosa, such an interpretation has not been so far applied, but the fact that mass wandering of $S$. globosa occurred at the water-logged place as in other ocypodids, as shown in the present study as well as in the previous ones (Sugiyama, 1961; Ono, 1965; Yamaguchi and Tanaka, 1974), suggests that it is probable.

Water is indispensable for feeding and respiration during the exposure time in ocypodids. They depend on burrows containing standing water or damp sand for the water. As the tide recedes, the surface of the substratum becomes dry and the water table descends deeper, which is more remarkable in such sandy substratum as $S$. globosa inhabits than in the muddy one. Consequently, the crabs may have to deepen their burrows for water supply, which is probably not easy for small crabs. As a result, the small or medium-sized crabs such as the juveniles or the females may tend to wander to the lower water-logged place. In case of overcrowding, the large crabs may also be forced to wander by more intensive interactions between them, perhaps not from the difficulty to deepen burrows. In the water-logged place, crabs can be easily supplied with water without burrowing. When men or predators approach them, the wanderers can hide themselves quickly in the sand because the substratum is easily dug up there. Thus, they do not need burrows from the viewpoint of refuge from predators as well as water requirement.

On the other hand, it is also probable that wandering is associated with the reproductive activity as suggested on $U$. tangeri by v. Hagen (1962). It has been known that males pair with wandering females in Ilyoplax pusillus (Wada, 1981), Macrophthalmus japonicus (Wada, 1978), and Uca species (Yamaguchi, 1971; Crane, 1975). Wandering of females is naturally expected to increase the opportunity of encountering males. In $S$. globosa, as observed in Fujishima in May and June, the sexual behaviors were frequently performed during mass wandering in which females dominated in numbers. This fact indicates that wandering of female $S$. globosa in the reproductive period is partly associated with mating.

\section{Summary}

1. The behaviors of wandering crabs of Scopimera globosa were seasonally observed in Fujishima, Tanabe Bay.

2. Many wanderers moved seaward at ebb tide, which resulted in their occurrence at the lower water-logged place at low tide. At flood tide they moved landward but some crabs burrowed at the lower place. Females were dominant in the wanderers in June, and in August and September newly settled juveniles were so.

3. From the observations of mass wanderings on other shores, the following cases differing from the previous descriptions were recognized: 1) females or juveniles were dominant in wanderers, 2) the population density in the neighboring area 
was relatively low, and 3) the weather was rainy.

4. Wandering of $S$. globosa is considered to be related not only to overcrowding but also to the water condition of substratum as has been hitherto suggested in some other ocypodids. Moreover, it may be also associated with mating in the reproductive period.

\section{REFERENCES}

Altevogt, R. 1957. Beiträge zur Biologie und Ethologie von Dotilla blanfordi Alcock und Dotilla myctiroides (Milne-Edwards) (Crustacea Decapoda). Z. Morph. Ökol. Tiere, 46: 369-388.

1959. Obologische und Ethologische Studien an Europas einziger Winkerkrabbe Uca tangeri Eydoux. Ibid., 48: 123-146.

Crane, J. 1975. Fiddler Crabs of the World. Princeton University Press, Princeton. 736 pp.

Hagen, H.O. v. 1962. Freiland Studien zur Sexual und der Fortpflanzungsbiologie von Uca tangeri in Andalusien. Z. Morph. Ökol. Tiere, 51: 611-725.

1970. Anpassungen an das spezielle Gezeitenzonen-Niveau bei Ocypodiden (Decapoda, Brachyura). Forma et Functio, 2: 361-413.

Miller, D.C. 1961. The feeding mechanism of fiddler crabs, with ecological considerations of feeding adaptations. Zoologica, 46: 89-100.

Nakasone, Y. 1977. Crab zonation in the Yuhi River, Okinawa Island. Jap. J. Ecol., 27: 61-70.

Ono, Y. 1965. On the ecological distribution of ocypoid crabs in the estuary. Mem. Fac. Sci. Kyushu Univ., Ser. E (Biol.), 4: 1-60.

Sugiyama, Y. 1961. The social structure of a sand-crab, Scopimera globosa De Haan, with special reference to its population. Physiol. Ecol. Japan, 10: 10-17. (in Japanese with English summary).

Tweedie, M.W.F. 1950. Notes on grapsoid crabs from the Raffles Museum. II. On the habits of three ocypodid crabs. Bull. Raffles Mus., 23: 317-324.

Wada, K. 1978. Two forms of Macrophthalmus japonicus De Haan (Crustacea: Brachyura). Publ. Seto Mar. Biol. Lab., 24: 327-340.

1981. Growth, breeding, and recruitment in Scopinera globosa and Ilyoplax pusillus (Crustacea: Ocypodidae) in the estuary of Waka River, middle Japan. Ibid., 26: 243-259.

Yamaguchi, T. 1971. Courtship behavior of a fiddler crab, Uca lactea. Kumamoto J. Sci., Biol., 10: 13-37.

and Tanaka, M. 1974. Studies on the ecology of a sand bubbler crab, Scopimera globosa De Haan (Decapoda, Ocypodidae). I. Seasonal variation of population structure. Jap. J. Ecol., 24: 165-174. (in Japanese with English synopsis and summary). 